\title{
Electric Power System Transformations: A Review of Main Prospects and Challenges
}

\author{
Nikolai Voropai \\ Energy Systems Institute, Lermontov Str., 130, 664033 Irkutsk, Russia; voropai@isem.irk.ru
}

Received: 14 September 2020; Accepted: 13 October 2020; Published: 28 October 2020

\begin{abstract}
The paper deals with the main prospects and challenges of radical transformations of electric power systems (EPSs) with changes in their structure and properties conditioned by wide use of innovative energy-related technologies and digitalization and intellectualization of system operation and control. Structural trends of EPS development are the focus of the analysis. Consideration is given to changes in EPS properties driven by the use of new technologies, to the problems of system flexibility and to its enhancement. EPS "resiliency" and "survivability" notions are subjected to comparison. The main factors favoring the formation of future EPSs to cyber-physical systems are discussed. Objective trends of EPS control and protection system development are under consideration.
\end{abstract}

Keywords: electric power systems; innovative technologies; transformation; trends; structure; properties; flexibility; survivability (resiliency); control and protection systems

\section{Introduction}

In the course of their development, electric power systems (EPSs) have continuously changed their structure and properties under the influence of objective factors. These include, for example, the broader use of innovative technologies for power generation, transmission, storage, distribution and consumption. This is followed by the rapid development of renewable energy sources and distributed generation, the new role of consumers in the power supply process that is driven by a new paradigm of client-oriented power supply, the role of EPSs as a critical infrastructure and some others [1-3].

The structure of future EPSs may be represented in an aggregate form as a three-level super-mini-micro-system (Figure 1 in [4]). Super systems include large power plants (thermal, hydraulic and nuclear), large parks of wind and solar power plants, energy storages of large capacity and transmission networks of high and super-high voltages, including delivery points transmitting power to the next level, to the level of mini-systems. Mini-systems include power mini-sources connected to a distribution network (thermal power mini-plants, mini-plants on the basis of gas turbine, gas piston, steam turbine and other technologies, mini-parks of wind and solar power plants), system power mini-storages, as well as distribution grids themselves, including distribution substations. In a mini-system, the unit capacity of mini-sources and power storage is unambiguously determined not to exceed $25 \mathrm{MW}[5,6]$. Micro-systems include micro-turbine power plants, isolated wind mills and photo panels, power micro-storages and internal electric networks of households or of their clusters and public and production facilities with a voltage of $6 / 0,4$ or $20 / 0,4 \mathrm{kV}$. The unit capacity of micro-sources and micro-storages even when taking into account multiple estimates can be assumed not to exceed $25 \mathrm{~kW}[7,8]$. 


\section{Super-Mini-Micro Grid Structure}

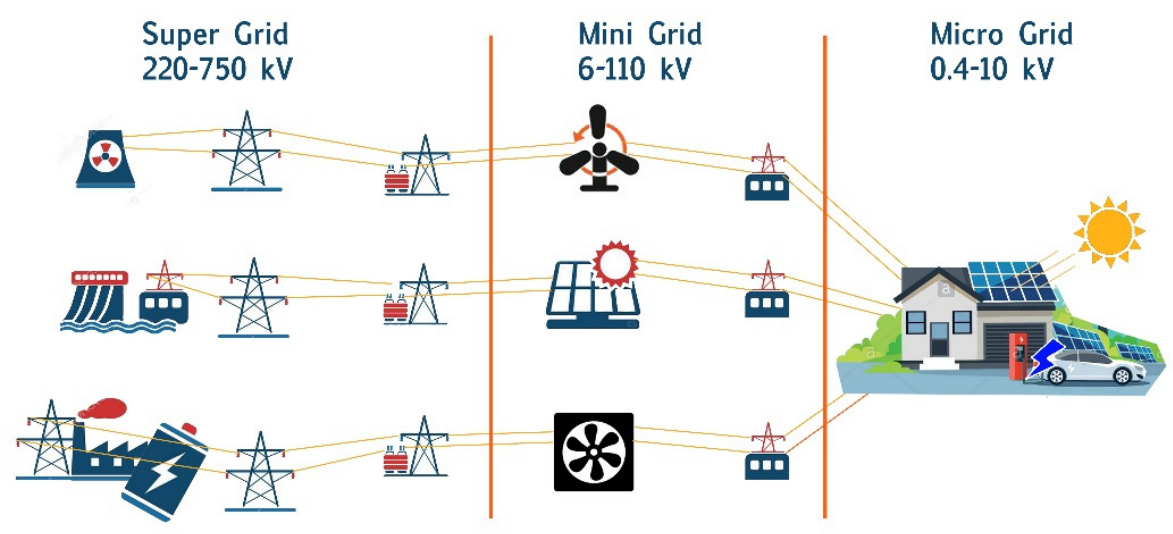

Figure 1. Three-level structure of future electric power systems [4].

The motivation of this paper is based on the rapid transformation of EPSs in the last 2-3 decades due to using innovative technologies. Taking into account this dynamic process, we can very quickly find ineffective and unreliable EPS operation. From the other side, because of the infrastructural role of EPSs, digitalization of industrial technologies for consumers and mode in life, and moving to the electrical internet, the requirements of consumers for the reliability of power supply and quality of electricity are very high.

This paper deals with qualitative estimations for the appearance for future EPSs. These estimations do not connect with any concrete period of concrete EPSs in any concrete country. Some new innovative technologies can be ready before the others or after. Taking into account these aspects, the author does not touch upon the economical side of the discussed problem.

In view of the above, the paper gives detailed consideration to the trends in the EPS structure transformation and changes in the main features of the architecture of future systems (Section 2). EPS properties depend on not only the structure of these systems, but also technologies of production, transportation, distribution, storage and consumption of electricity. Therefore, the transformation of the future EPS properties under the influence of innovative technologies and new problems of EPS flexibility are discussed (Section 3). Possible measures for flexibility enhancement of the future EPSs are presented (Section 4). A tendency in growing the number and consequences of EPS blackouts worldwide leads to the necessity to consider the EPS resiliency problem, which corresponds to the term "survivability" (Section 5). Possible measures for enhancing the resiliency/survivability are suggested (Section 6). Considering the EPS resiliency/survivability problem, it is important to analyze cascading emergencies and EPS restoration (Section 7). Taking into account rapid development of information-communication sub-systems of EPSs due to information technologies and digitalization of these systems, it is necessary to discuss cyber-physical EPSs (Section 8). Last, but not least, the development trends of EPS management and control systems are discussed in this paper (Section 9).

\section{Structural Trends in the EPS Development}

Let us first consider the main trends in the EPS architecture transformations at the level of a super system. A number of objective factors, both conventional and new ones, define those tendencies. A key conventional factor is the implementation of technical system effects occurring during joint operation of different EPSs [9,10]. Technical effects are assumed to include capacity, structure, frequency and operational and environmental effects. According to the estimates given in [9], the use of those effects in the unified power system (UPS) of the former USSR at the end of the 1980s allowed for the reduction of the required installed capacity of power plants by 10-12 GW. A similar effect for the 
West European Energy Interconnection (UCPTE) in 1989, according to the estimates of the European Economic Commission, was as high as 34 GW [11].

It should be noted that proposed estimates of using the system technical effects owing to joint operation of EPSs are, in a sense, the maximum possible ones. The degree of their implementation depends on the structure and mechanisms governing the electric power markets [10,12]. System effects are hereby considered as system services. The Association of System Operators of the largest EPS in the world, G015 [13], draws attention to a new understanding of the considered system services with reference to Electric Power Research Institute (EPRI, USA) studies that single out five categories of services provided by electric power systems at the level of super systems, namely:

- warranted access to electric power of EPSs as an infrastructure system at any time, in any amount, at required reliability and quality;

- availability of starting currents to start up large electric engines and power plants that lost power for ancillary services in the course of an emergency;

- provision of high-quality voltage and frequency;

- $\quad$ higher efficiency of EPS operation;

- ability to select counteragents and to minimize local monopolism of separate segments of the electric power market.

The creation of mega centers of power generation on the basis of renewable energy sources, for example, large-scale hydropower plants - HPP ("Three Gorges" HPP on the Cháng Jiāng River in China, a large HPP on the Congo River in Central Africa and others) and mega parks of windmills in the North Sea and on the Arctic coast of Russia, solar power plants in the Sahara and Gobi Deserts, and others, is a relatively new factor [14,15]. Figure 2 gives an example of a mega project of West European Electric Power Interconnection development on the basis of wind turbines in the North Sea and solar power plants in the Sahara Desert [16].

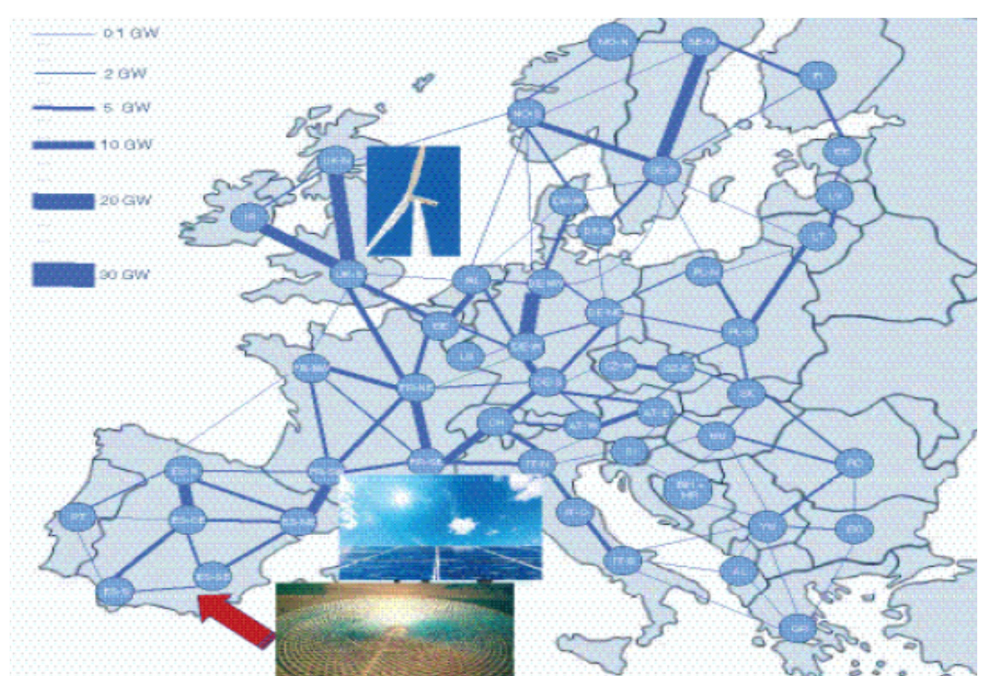

Figure 2. Mega-project of West European Electric Power Interconnection [16].

Electric power generated by these mega centers shall be transmitted long distances, which is a driving force for creating the super-high voltage Global Energy Interconnection [17] (Figure 3). We should like to note that [18] demonstrates, in a sense, fantastic potential of renewable power generation by 2050 for 143 countries. Furthermore, according to estimates given by the authors of [18], refusal of conventional energy sources would allow for the reduction of energy consumption by more than $55 \%$. 


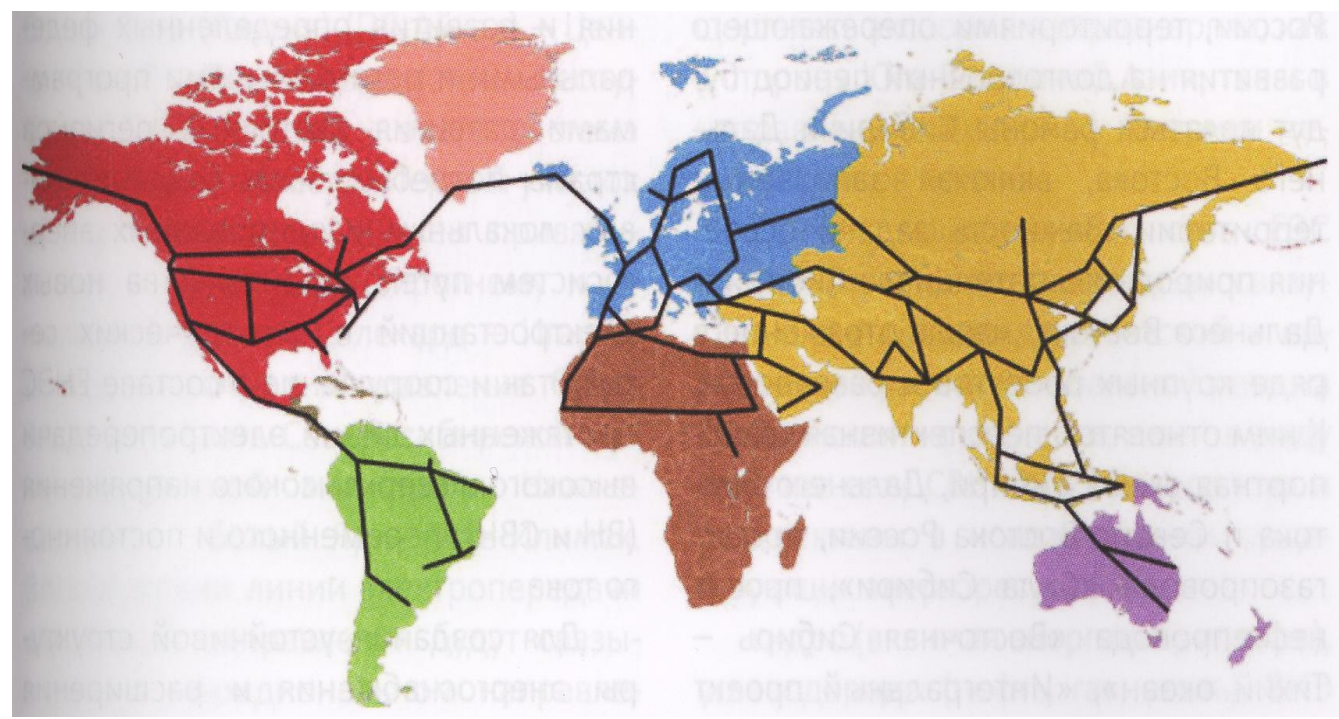

Figure 3. Possible scenario of Global Energy Interconnection development [17].

The above factors and tendencies are expected to have high probability of implementation, particularly owing to the active development and reduction of production costs of technologies for long-distance transfer of ultra-high voltages, direct and alternating currents [19].

The scenario of the intensive development of distributed generation in the marginal case up to the gradual abandonment of large power plants and main super-high-voltage electric networks is sometimes considered to be, in a sense, the opposite one. The implementation of such a marginal scenario in the foreseeable future is deemed to be improbable despite obvious and well-known objective benefits of developing distributed generation (more stringent environmental requirements stipulate more rapid development of renewable energy; rapid adaptation to power demand uncertainty owing to the commissioning of generating units; unloading of the main electric network of a super system; general reduction of capacity and power losses and some others). A scenario of collaborative development of relatively large power plants at the level of super systems (centralized power supply) and distributed generation units at the level of mini-systems (decentralized power supply) is thought to be realistic and have a high probability of implementation.

According to the estimates given in [20], the ratio between centralized and decentralized power supplies shall follow the "golden section" rule: $0.62 / 0.38$ for the systems with high-density loads and, vice versa, $0.38 / 0.62$ for areas with distributed consumers. As far as the stage of rapid industrial development is substituted by the development of systems with poorly concentrated loads, the decentralized power supply acquires stimuli for dynamic development. Despite the fact that power production by large power plants is far more efficient, the principle of convenience for consumers dominates over the economic principles. Furthermore, power supply for large consumers (whose power supply cannot be ensured by renewable sources) needs to be of high quality (in terms of voltage and frequency), and this will be the main reason for keeping large centralizer power sources in the EPS.

An ever-growing density and complex closing of the main and distributed electric networks due to the growth of loads that require commissioning of additional lines on the background of total reduction of their length becomes a general structural tendency of super and mini-systems. As a result, energy continues to develop in densely populated areas (e.g., in Western Europe), whereas in the regions with territorially extended EPSs, the energy hubs are connected by the available long-distance lines and cutsets (e.g., in Russia, Brazil, etc.), which is typical of power supply systems of megacities and results in the occurrence of new properties in the energy interconnection as a whole. Power supply systems of megacities with short lines and developed structure are characterized by a lack of "angular" stability problems, whereas the probability of the occurrence of "voltage" instability is rather high. 
This is confirmed by an analysis of the 2005 Moscow blackout [21], by large-scale emergencies in the West European Interconnection [22] and by some other examples.

The territorial expansion of interconnections raises the following question: are there technical limits for such expansion? [23,24]. Studies have shown that there are neither physical nor technical constraints for EPS expansion. The maximum distance of power transmission within the interconnection is determined by a comparison of technical and economic factors. These include the relative location of generating sources and power consumption centers, cost of power transmission, transmission capacity limits, amount of active power losses during transmission and some others. As a result, local zones of free power flows may be formed in an extended interconnection; unlimited power exchange within such zones is technically feasible and economically beneficial, but between those local zones are limitations on load flows.

Thus, the structure of large interconnections in the general case becomes more and more heterogeneous, cases of voltage instability in the concentrated parts of the interconnection become more and more probable, and problems of angle stability are maintained in long-distance sections with extended electric ties. As a result, the nature of EPS behavior in emergencies become more sophisticated, which requires the adjustment and development of mathematical models of transient processes in the system, and updating of the methods for studying the behavior of such EPSs under disturbances.

A more complicated structure of developing EPSs on the background of general growth of installed capacity and scales of energy interconnections aggravate consequences of system cascading emergencies, which is confirmed by the USA statistics for 1991-2005 (Figure 4) [25]. Unfortunately, the author did not find more recent data, such as in EPSs [25], but he believes in this objective trend for complicated EPSs with a large value of generating installed capacity and heterogeneous electrical network structure under the influence of innovative technologies.

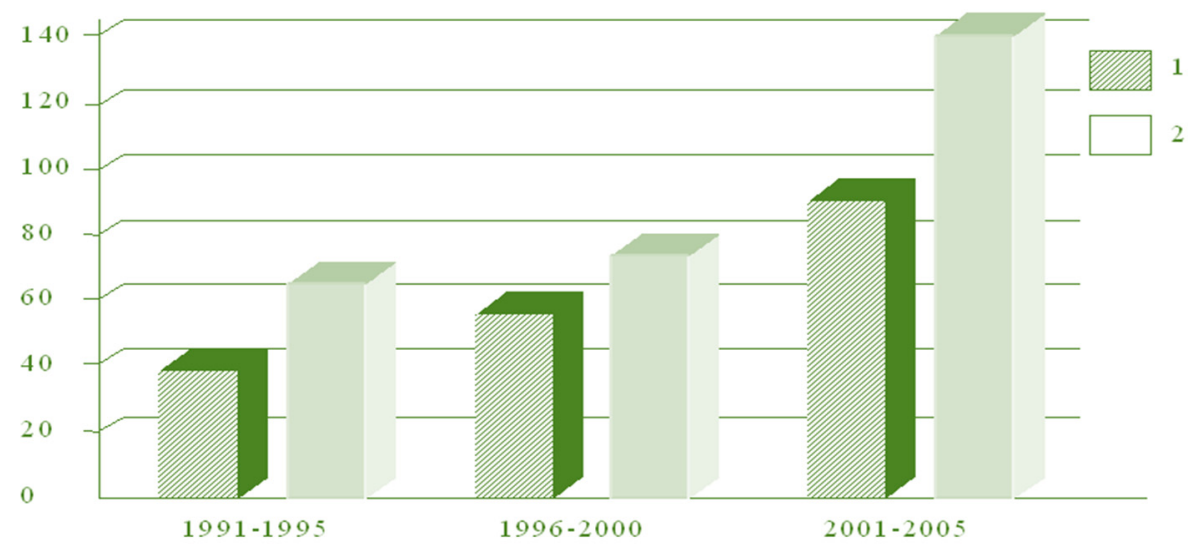

Figure 4. Tendency for electric power system (EPS) blackout problems [25]. (1) The number of outages affecting more than 50,000 consumers; (2) The number of outages greater than $100 \mathrm{MW}$.

Micro systems are traditionally designed to run with an alternating current. Many electrical power devices of consumers currently operate on a direct current, and for connection to EPSs, reversible converters are used. For this reason, micro-systems are mainly developed on the direct current or as hybrid AC/DC micro-systems [6-8].

Micro-systems may operate together with EPSs on the level of a mini-system or independently. Isolated micro-systems are characteristic of the power supply systems of islands (e.g., Greece [7], South Korea [10]). The project in Mongolia called "1,000,000 solar photo-panels" [26] is a unique project of DC micro-systems for the power supply of isolated consumers. A standard mix of electric devices of a present-day yurt of an isolated power consumer under that project includes the following appliances (maximum): lighting, an electric stove, a refrigerator, an electric heater and a digital TV. For balancing the irregularities of power supply from photo panels, the micro-systems use electric storage devices. 
The author of [7] gives data (for the moment of publication) on some implemented pilot projects of power supply micro-systems in some countries of the world:

- In Europe:

- Kitnos (Greece) with decentralized intelligent load control;

- Mannheim (Germany) - transition from joint operation with EPS to islanded operation;

- Bronsberger (Netherlands) - islanded operation of a micro-system and of an intelligent electric storage facility.

- In Japan:

- demonstration projects of micro-systems, including a demonstration project in New Mexico.

- In China:

- micro-systems on islands, in industrial, commercial and residential areas and in remote areas.

- In the USA:

- a roadmap of studies and demonstration projects of power supply micro-systems.

Certain activity on developing the power supply micro-systems is also observed in Russia [27].

Thus, structural changes of future EPSs at all three levels-in super, mini- and micro-systems—cause changes in their properties and originate new challenges that require solutions.

\section{Transformation of the Future EPS Properties under the Influence of Innovative Technologies. EPS Flexibility}

Alongside basic structural changes in the future EPSs, radical transformations can be expected in their properties. Some new objective factors emerged lately that stimulated studies on EPS flexibility and on justifying the means for its enhancement.

EPS flexibility is a relatively new notion characterizing EPSs' ability to maintain normal or close to normal operating conditions under the effect of internal (sudden changes and fluctuations of the load, power flows in the lines and in generation) and external (sudden disturbances of different origin) random (uncertain) factors [28]. It should be noted that EPS flexibility in its essence is close to security of the systems. EPS flexibility, along with other aspects of its definition, reflects "internal activity" of the system which is evidenced by its ability to self-adapt to influencing factors and by undertaking a number of "active" measures to raise the EPS flexibility. In this respect, the security is a kind of "external", "passive" assessment of the system's ability in the considered sense [29].

The self-healing of a present-day EPS and its ability to dampen internal and external disturbing factors are dependent on the actions of regulating effects of load in terms of voltage and frequency and frequency characteristics of speed controllers of synchronous generators, as well as by inertia of rotating masses of rotors of synchronous and asynchronous machines, and by the actions of control by emergency control systems, and by automatic protection devices. Owing to the EPS self-healing property, it adapts to sudden changes in conditions and to disturbances within the admissible (standardized) ranges of their values, and when parameters of conditions and disturbances go beyond the permissible limits, the emergency control system is activated that prevents the cascade propagation of the emergency by its localization and liquidation [1].

Present-day EPSs, subject to the use of conventional energy and electric power technologies, means and control systems, are characterized by rather high flexibility owing to the mentioned self-healing and self-stabilization relative to internal and external destructive factors.

Electric power systems of the 21st century undergo radical changes in their properties not only due to the transformation of their internal structure, but also due to use of innovative technologies in electric power generation, transmission, storage, distribution and consumption. Those changes 
considerably lower the ability of future EPSs of self-adaptation and self-stabilization and lower their flexibility level. Internal EPS factors that cause those consequences are related to large-scale use of power electronics and rectifying invertors for connection with EPSs of high-speed gas turbine and gas piston generating units, wind generators, photovoltaic units, power storage devices, DC lines and links and frequency-controlled electric motors.

Growth in the scope of EPS use at the levels of super systems and mini-systems of the above named technologies and units considerably lowers the above listed frequency and voltage control effects of consumers, frequency-controlled characteristics of generators and inertia abilities of the system that, as a consequence, lower its flexibility [1,28].

On the other hand, growth in the share of randomly fluctuating generation of renewable energy sources (windmills, solar photo panels, small-scale hydropower plants) raises the negative impact of those fluctuations in the generating capacity on self-adaptation and self-stabilization of the system, i.e., on the EPS flexibility. Therefore, a new problem of damping the power imbalances occurring as a result of such random fluctuations arises. The solution for this kind of problem is the use of power storage on the basis of rapidly developing innovation technologies. Control systems using power electronics Flexible Alternating Current Transmission System (FACTS), which were in detail studied in [30], power storages, DC lines and links have a high efficiency of control and stabilization. Large-scale use of such devices in the future EPSs would radically enhance the controllability of those systems and, hence, their flexibility, stability and survivability $[1,28]$.

\section{Possible Measures for Flexibility Enhancement of the Future EPSs}

In order to ensure the EPS flexibility, it is necessary to consider capabilities of generation of an electric network and loads; it can also be ensured by protection and control systems; it is also necessary to estimate the effects of the integrated use of different means at different levels. Those capabilities include the following [28]:

- As was noted above, frequency characteristics of speed and frequency control systems of conventional synchronous generators play a major role in ensuring the EPS flexibility as they enhance the self-adaptation and self-stabilization ability of systems for damping the negative impact of internal and external factors. The flexibility of generating units can additionally be enhanced by a higher speed of loading and unloading, by their deeper unloading, by maintenance of the required levels of rotating and operating reserves of active generating capacity, by reliable fuel supply for power plants and by power plant restoration from the "black-start" level in the case of auxiliary power loss due to faults.

- The flexibility of transmission and distribution networks can be enhanced by the liquidation of weak points in the network, by the reduction of transfer capability constraints of weak cutsets and by a higher efficiency of using the transfer capability of weak links. The application of FACTS devices, which are manufactured now by various companies [30], whose control systems allow for the stabilization of EPS mode variables and maintain the required transfer capability margins of links in normal, maintenance, emergency and post-emergency conditions, is a reliable means to ensure that. Higher flexibility of active transmission and distribution electric networks can be ensured by automatic reconfiguration of the network [31].

- Load flexibility is ensured by the abovementioned frequency and voltage control effects, by automatic load control owing to shifting the controllable electric facilities to the zone of a minimum daily load curve [32] and by using the distributed generation units available with the consumers (prosumers) [33].

- Power storages of different capacities and energy intensities will play a major role in enhancing the EPS flexibility, particularly in the case of random fluctuations in power supply by units based on renewable energy sources (RESs) at all levels, i.e., in super, mini- and micro-systems [34]. 
- Integrated multi-energy systems allow for additional means for enhancing the EPS flexibility when using units generating the required type of energy by the use of another type of energy (for example, heat pumps, electric boilers, etc.) [35]. Innovative gas supply systems within integrated energy systems allow for further enhancement of power generation flexibility owing to more efficient gas-based technologies, especially with the combined production of heat and power [33,35].

- Efficient protection and control systems play a key role in ensuring the EPS flexibility [36]. The efficiency of those systems when using the intelligent technologies can be notably enhanced by raising the accuracy of EPS state variable forecasts, by the reduction of time for preparation of control actions, and by raising the frequency of their implementation [28].

- In this connection, a detailed review given in [37] is worth mentioning that gives 393 names of quoted papers. The authors analyze practically all the above listed measures for enhancing the EPS flexibility.

- The use of market mechanisms is an efficient means for stimulating the EPS flexibility enhancement [38].

Consequently, there are numerous capabilities to enhance the flexibility of future EPSs and selection of the most expedient means is not a simple task to be solved for standard conditions of transformed EPS operation and development. However, extreme conditions occurring under the effect of internal and external factors remain topical and need detailed consideration.

\section{Resiliency and Survivability of EPSs}

The tendency of the consequences of cascade systems emergency in EPSs (Figure 4) to be aggravated was determined by conventional factors related to larger scales, structural complexity and territorial extension of the considered systems. The abovementioned basic changes in the structural characteristics and internal properties of future EPSs would exacerbate this negative tendency. The described circumstances have lately initiated discussions and studies on the problems related to a new EPS "resiliency" (elasticity) notion. The most succinct interpretation of "resilience" is given in [39], where it is defined as a property of any system to withstand any changes or interrupted events by reducing their initial negative impact and by mitigation of consequences for the system (damping ability), self-adaptation of a system to those changes and events to mitigate consequences (self-healing ability) and system restoration by appropriate controlling actions during the minimum time possible (restoration ability). The main details of this definition are shown in Figure 5.

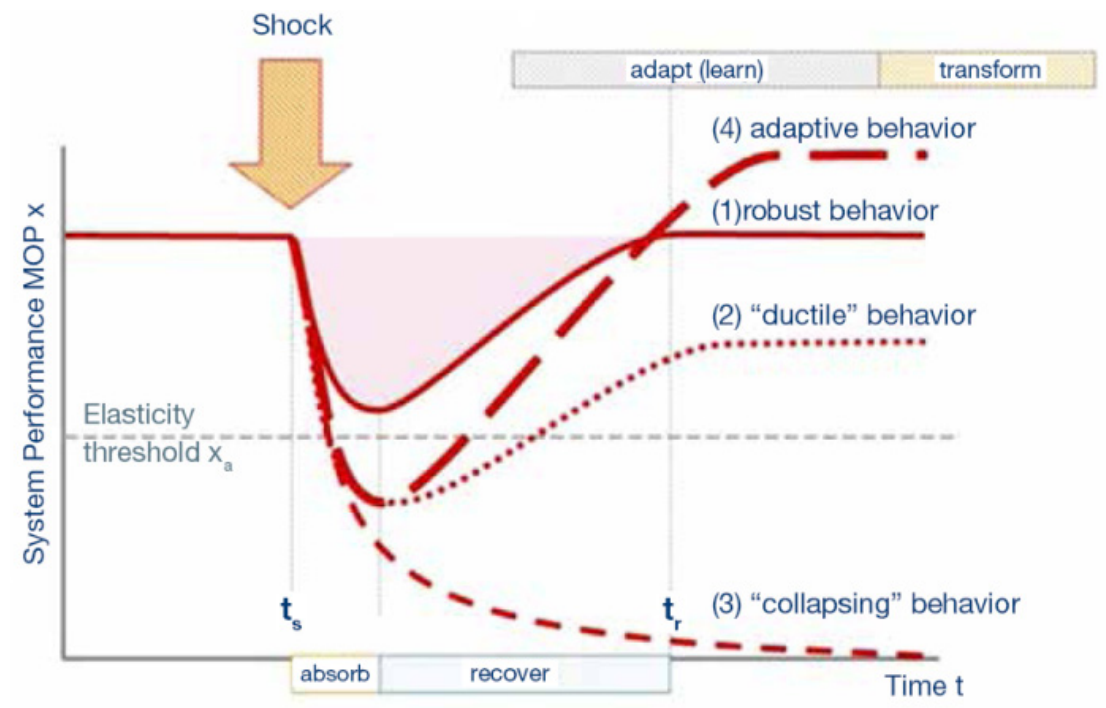

Figure 5. Main regularities of the system's stable and unstable behavior in terms of resiliency [39]. 
In [25,40-42], the resiliency problem is studied as applied to EPSs; to be more particular, in [25,42], it is studied considering the cascade system emergencies, and in $[40,41]$ for the cases of natural disasters.

A Russian term corresponding to "resiliency" as applied to EPSs is "survivability" that is defined as the ability of the system to withstand emergencies preventing their cascade propagation which are followed by a large-scale interruption of power supply to consumers, and the ability of the system to restore its initial state or the state close to it [43]. Let us make some comments on what is illustrated in Figure 6 to explain the term "survivability of EPS": line 1 shows the level of a normal operation state before the emergency; line 2 presents the so-called marginal (limiting) state, which is lower then the triggering event and the EPS meets a catastrophic uncontrollable cascading process, which notes by number 4; line 3 shows the cascading process before the marginal state and triggering event, when the emergency control system and operating personnel try to prevent (interrupt) the cascading disturbance and to restore the normal state of the EPS (lines 6); line 5 presents an extreme disturbance like a storm, earthquake and so on; line 7 shows the recovery (restoration) stage.

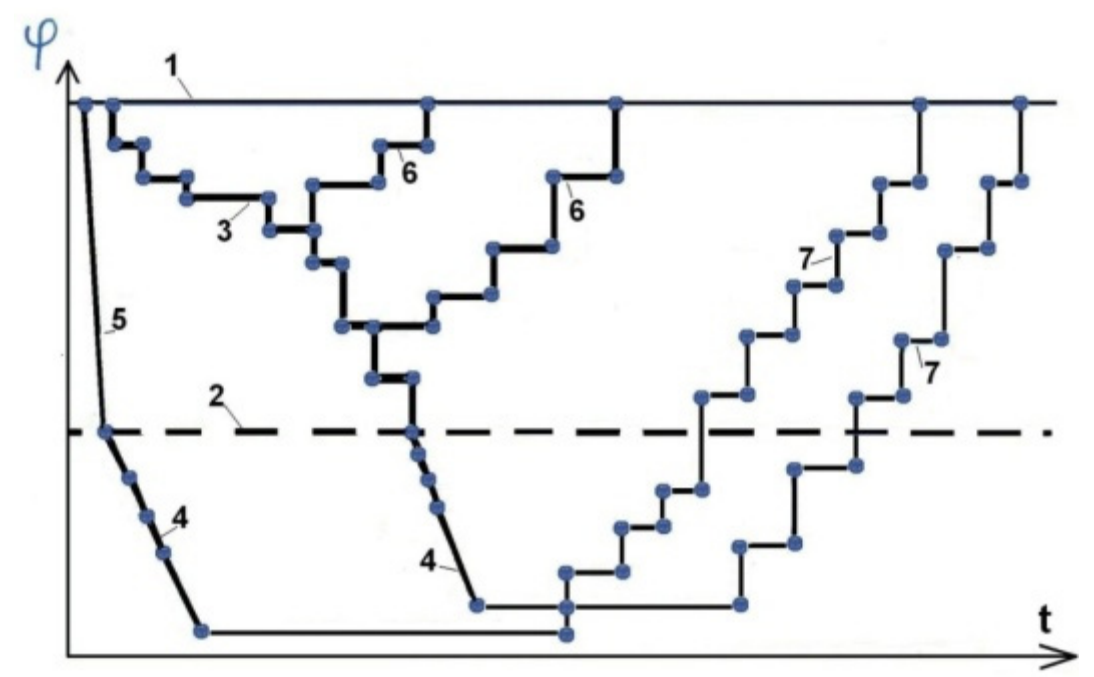

Figure 6. Illustration of EPS behavior in terms of survivability $[43,44]$.

The abovementioned definition shows that survivability includes damping and adaptation abilities of the system that were considered in [39] as applied to resiliency, and its ability to recover. A comparison of key components of the two terms additionally proves their identity (Figures 5 and 6): the elasticity margin and marginal state; the move to collapse and catastrophic cascade process; adaptive behavior and recovery; robust behavior and opposition to cascade propagation of the emergency (the first component of the comparison belongs to resiliency, the second one to survivability).

The relations between EPS resiliency and flexibility are of interest. An analysis of definitions of those properties shows that a higher flexibility of the system causes growth in damping and adaptation ability of the EPS that are characteristic of resiliency.

\section{Possible Measures for Enhancing the Resiliency/Survivability of EPSs}

These measures include [28]:

- Elaboration of reliability standards for submission of the reliability requirements when planning the EPS development and condition control; it is necessary to note the necessity of elaborating special reliability standards for the cases of natural disasters with the identification of specific requirements for the power supply reliability of major consumers in those conditions;

- Creation of a large-scale efficient protection system and emergency control system that is primarily important for preventing the cascade propagation of an emergency; 
- Development of efficient procedures for EPS recovery after large disturbances. It is obvious that those procedures shall be different for the cases of system recovery after a cascade emergency and after natural disasters;

- Organization of regular training for dispatchers. The contents of that training shall be different for the cases of a cascade emergency and for natural disasters;

- Generalization of the nature and mechanisms of occurrence and development of large emergencies. Each system cascade emergency is unique but their analysis and generalization allow for the identification of the key factors whose elimination would reduce the probability of such emergencies and mitigate their probable consequences. Considering the basic importance of such generalizations, let us consider this aspect of the problem in greater detail.

\section{Analysis of Cascading Emergency Mechanisms and EPS Restoration}

Many different disturbances occur in complex extended EPSs every year for different reasons: short circuits of electric equipment, failure of system elements, errors of operating and servicing personnel, etc. The major share of those disturbances is eliminated by relay protection and emergency control devices (ECDs). If efficiency and reliability of relay protection and ECDs are not sufficient, a cascade propagation of the emergency occurs that is interrupted by the next stage of the ECD or/and by the control actions of personnel. Such circumstances in an integrated interconnection (e.g., Unified Energy System (UES) of Russia or Electric Power Interconnection of the Northeast USA and east of Canada) may take place up to several times during a year. Such cascade emergencies, as a rule, do not cause sensible consequences for consumers and the system, and remain unnoticed by the public. If an emergency control system and operating personnel cannot interrupt the cascade emergency, it becomes irreversible and blackouts occur that often have catastrophic consequences for a system and consumers; examples of such system emergencies are the 2003 blackouts in North America and Europe, the Moscow emergency in 2005 and some others [21,22].

It should be noted that there are two basically different ideologies for opposing the cascade propagation of system emergencies, namely, whether a dispatcher plays a leading role in this process, or an automatic control system. Russian experience shows that automatic interruption of cascade emergencies is more preferable due to their fast occurrence. The probability of erroneous actions of an operator in high-stress circumstances is rather high, which exacerbates the situation [44,45].

Although the role of emergency control systems in preventing the occurrence and propagation of heavy system cascade emergencies is the major one, and analysis and generalization of mechanisms effecting the basic peculiarities of the states, events and processes during such emergencies become of major importance. The most typical approaches to such generalizations are considered in [42,45-50]. Key provisions of those generalizations can be stated as follows.

1. Several of the most characteristic events and stages of occurrence, and cascade propagation of the system emergency, are to be singled out: initial disturbance (initiating event); cascade process of the emergency propagation with implementation of control actions to prevent the steady-state progression; marginal state ("point of no return"); a triggering event; catastrophic uncontrollable avalanche-like high-speed cascade; EPS restoration (Figure 7) [44].

2. The authors of [47], on the basis of statistics of large emergencies in North America in 1984-2006, analyze a number of hypotheses and discard the hypotheses on frequency reduction of such emergencies with time; on independence of the frequency of emergencies from the season of the year; on independence of the frequency of emergencies from the time of the day; on the correlation between the scale of the emergency consequences and time for the system restoration.

3. The authors of $[42,44,48-50]$ stress the decisive role of emergency control systems in preventing the occurrence of emergencies, in opposing the propagation of heavy emergencies and in rapid restoration of the system. An emergency control system is to perform three groups of functions: 
prevention of a cascade emergency in the pre-emergency conditions; adaptive opposition to emergency propagation; adjusting the control in the post-emergency conditions;

4. The authors of $[42,46]$ note certain correlations between factors of EPS liberalization in terms of actualization of congestion problems due to the growth of power exchange volumes at the spot market and growth in the large system emergency probability.

5. The role of the EPS restoration process step by step from the final state with the active participation of a dispatcher and by an automatic emergency control means [42-44,48-52]. The restoration process shall not be interrupted by irrational control actions that aggravate the emergency situation.

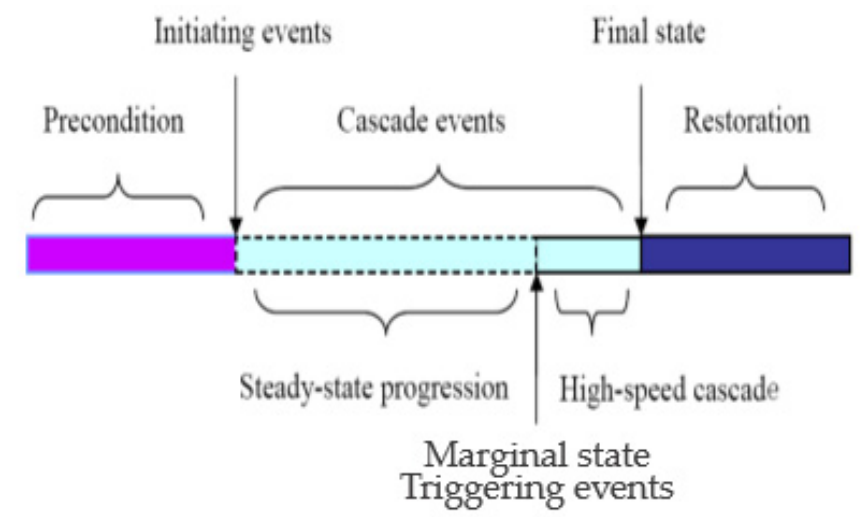

Figure 7. Typical stages of a cascading system emergency [44].

The described elements of the analysis and generalization of the mechanisms of occurrence and propagation of cascade emergencies and EPS restoration comply with the survivability/resiliency notions.

\section{Cyber-Physical EPSs}

A present-day electric power system is a complex facility consisting of two closely related subsystems: physical (technological) and information-communication (ICS). The sophistication and role of present-day and future technological and information-communication subsystems in ensuring the normal EPS operation are comparable [53].

In the conditions of energy industry digitalization that implies both faster interpretation of digital information and higher efficiency of technological processes in EPSs that use the innovative power equipment of new generation operated as per the standards of the International Energy Commission (IEC), and considering the development of new software for controlling newly created digital substations, local electric grids, etc., an EPS shall be perceived as a complex cyber-physical system whose ICS may not operate properly due to internal defects (errors in the algorithms, etc.), and may be subjected to external effects, namely, cyberattacks $[54,55]$. The possibility of internal and especially of external factors (cyberattacks) causing an improper operation of ICS raises EPS cyber security concerns [56].

The analysis of events occurring during the propagation of cascade emergencies in different countries $[25,42,44,47]$ shows the possibility of a mutual impact of failures and disturbances in the physical and information-communication subsystems of EPSs. The uncertainty of information on the current EPS conditions or on its loss due to internal defects of digital devices or on external cyberattacks against ICS may be the cause of erroneous control actions and the development of a fault process in a physical subsystem. The failure or fault of an element in the physical subsystem may lead to emergency conditions in this subsystem and to a failure of ICS components. Considering these relations, physical and information-communication factors shall be integrated at the level of justifying the development of cyber-physical EPSs $[56,57]$ and for the solution of different problems of operating condition control $[55,58]$. 
Thus, the scope of factors necessitating the transformation of EPS structure and properties and generating a list of urgent problems to be studied for ensuring the flexibility and resilience of those systems becomes much larger for the present-day systems or even worse in future.

\section{Development Trends of EPS Management and Control Systems}

The abovementioned evidence shows the key role of control in ensuring the normal operation of complex cyber-physical EPSs of the future. Along with the transformation of EPSs, the control systems, principles of their design, methods and means of their implementation will be transformed as well. The complication of EPS structure and processes due to new properties of the systems is one of the main trends of EPS development. Those complicating factors shall be considered in developing the principles and methods of control. According to W.R. Ashby [59], sophisticated principles embedded in a control system shall be adequate to develop the sophistication of a controlled facility and processes occurring in it.

When considering the structure of future control systems for EPS conditions, the majority of investigators agree that those systems shall have a hierarchical structure [42,48,60-62]. For the general case, they consider three stages of control [42,61]: preventive control in pre-emergency conditions; adaptive control during emergency, and corrective control in post-emergency conditions. As applied to the problem of opposing the cascade propagation of emergencies in EPSs, they discuss coordinated hierarchical control $[42,60]$. They also stress the role of artificial intelligence in enhancing the efficiency of control [62].

When identifying the perspective trends in the development of principles of control and in EPS control systems, they use:

- $\quad$ wide area monitoring, protection and control systems (WAMS, WAPS and WACS);

- ideology implemented on the basis of phasor measurements of EPS state variables;

- present-day data transfer;

- processing and visualization means for monitoring current operating conditions;

- adaptive methods for generating the control actions. Adaptation in this case is based on prediction, which requires the use of applicable methods for forecasting the EPS state variables.

An example of perspective approaches may be an intelligent system proposed in [63]. The system is based on multi-agent technologies and algorithms of computer-aided learning for early prevention of critical voltage instabilities. Large-scale use of grid-related control means (energy storage systems, FACTS devices, etc.) and potentials of active consumers is also typical of such approaches.

In the roadmap that was discussed, special consideration shall be given to the operating and designed emergency control system for EPSs of Russia that, along with other components, includes a key subsystem of adaptive automatic emergency control $[36,44,64]$. This subsystem has a hierarchical structure. Its lower level is represented by numerous automatic devices based on micro-computers and on implementing specific control actions to localize and liquidate an emergency, and to prevent its propagation. Control actions of the upper level that are performed by devices of the lower level are adjusted in a cyclic way with regard to the current EPS conditions, thus ensuring adaptive control. Furthermore, an echeloned principle of automatic device operation is implemented: if a subsystem of automatic prevention of stability loss failed to ensure EPS stability at the first stage, the next group of automatic devices starts operating to oppose the dramatic emergency cascade. Therefore, a system of automatic emergency control operating in EPSs of Russia even now has many functions and peculiarities of a future control system.

The basic concepts of control system transformation described above belong predominantly to the level of super systems and can be considered as basic ones for designing the control systems for mini-systems. The ideology of control systems for micro-systems has been rapidly developed in recent years. The designed control systems are implemented on the basis of multi-agents using algorithms of consensus control that imply the use of appropriate agents' consensus protocols during control $[65,66]$. 


\section{Concluding Remarks}

EPS development on the basis of innovative technologies and means in a physical and information-communication subsystem in the conditions of digitalization and intellectualization of EPS operation and control of their modes will necessitate radical transformation of their structure and properties. Future electric power systems in the long run will become sophisticated intelligent cyber-physical EPSs that could radically differ from present-day systems. This transformation will require a comprehensive review of available principles and methods for modeling such systems, for studying their new properties and for justifying their development and control of their operation. Technologies like artificial intelligence shall become the basis of new models and methods, along with traditional ones. New future control systems shall become a key factor in ensuring normal operation of transformed EPSs. The ideology of their construction and operation shall go before the needs of transformed cyber-physical EPSs.

Funding: This study was undertaken by the Russian Scientific Foundation, Project \#19-49-04108.

Conflicts of Interest: The author declare no conflict of interest.

\section{References}

1. Voropai, N.I.; Osak, A.B. Electric power systems of the future. Energeticheskaya Polit. 2014, 5, $22-29$. (In Russian)

2. Marvasti, A.K.; Fu, Y.; DorMohammadi, S.; Rais-Rohani, M. Optimal Operation of Active Distribution Grids: A System of Systems Framework. IEEE Trans. Smart Grid 2014, 5, 1228-1237.

3. Quint, R.; Dangelmaier, L.; Green, I.; Edelson, D.; Ganugula, V.; Kaneshiro, R.; Pigeon, J.; Quaintance, B.; Riesz, J.; Stringer, N. Transformation of the Grid: The Impact of Distributed Energy Resources on Bulk Power Systems. IEEE Power Energy Mag. 2019, 17, 35-45.

4. Voropai, N.I.; Stennikov, V.A. Integrated smart energy system. Izv. RAN Energ. 2014, 1, 64-72. (In Russian)

5. Ackermann, T.; Andersson, G.; Söder, L. Distributed generation: A definition. Electr. Power Syst. Res. 2001, 57, 195-204.

6. Marnay, C.; Nordman, B.; Lai, J. Future roles of mili-, micro-, and nano-grids. In Proceedings of the CIGRE Symposium "Electric Power System for the Future-Integrating Supergrids and Microgrids", Bologna, Italy, 13-15 September 2011.

7. Microgrids: Architectures and Control; Hatziargiriou, N. (Ed.) IEEE Press-Wiley: New York, NY, USA, 2014.

8. Marnay, C.; Abbey, C.; Joos, G. Microgrids 1: Engineering, economics, and experience-Capabilities, benefits, business opportunities and examples-Microgrids evolution roadmap. Electra 2015, 283, 71-75.

9. Ershevich, V.V.; Antimenko, Y.L. Operation efficiency of Unified electric power system on the territory of former USSR. Izv. RAN. Energ. 1993, 1, 22-31. (In Russian)

10. Voropai, N.I.; Podkovalnikov, S.V.; Osintsev, K.A. From interconnections of local electric power systems to Global Energy Interconnection. Global Energy Interconnect. 2018, 1, 4-10.

11. Commission of the European Communities. The Benefits of Integration in the European Electricity System; Work Document; Commission of the European Communities: Brussels, Belgium, 1990.

12. Voropai, N.I.; Trufanov, V.V.; Selifanov, V.V.; Sheveleva, G.I. About the efficiency analysis of Unified electric power system of Russia. Elektrichestvo 2000, 5, 2-9. (In Russian)

13. Opadchy, F. The Necessity in the Large Power Systems Does not Decrease, but Increase, Interview of Vice-President of International Association for System Operators G015 F. Elektroenergiya. Peredacha Raspred. 2020, 1, 146-150. (In Russian)

14. Mano, S.; Ovgor, B.; Samadov, Z. Gobitec and Asian Super Grid for Renewable Energies in Northeast Asia. Available online: https://www.renewable-ei.org/images/pdf/20140124/gobitec_and_ASG_report_ENG_ BOOK_final.pdf (accessed on 15 October 2015).

15. Deng, C.; Song, F.; Chen, Z. Preliminary study on the exploitation plan of the mega hydropower base in the lower reaches of Congo River. Glob. Energy Interconnect. 2020, 3, 12-22. 
16. Strbac, G.; Pudjianto, D.; Aunedi, M.; Papadaskalopoulos, D.; Djapic, P.; Ye, Y.; Moreira, R.; Karimi, H.; Fan, Y. Cost-Effective Decarbonization in a Decentralized Market: The Benefits of Using Flexible Technologies and Resources. IEEE Power Energy Mag. 2019, 17, 25-36.

17. Liu, Z. Global Energy Interconnection; Elsevier: Amsterdam, The Netherlands, 2015.

18. Jacobson, M.Z.; Delucchi, M.A.; Cameron, M.A.; Coughlin, S.J.; Hay, C.A.; Manogaran, I.P.; Shu, Y.; Von Krauland, A.-K. Impacts of Green New Deal Energy Plans on Grid Stability, Costs, Jobs, Health, and Climate in 143 Countries. One Earth 2019, 1, 449-463.

19. Liu, Z. Ultra-High Voltage AC/DC Grids; Elsevier: Amsterdam, The Netherlands, 2015.

20. Bushuev, V.V. Energy-information systems as the basis of neo-industrial and socio-humanitarial civilization. Energeticheskaya Polit. 2016, 3, 7-24. (In Russian)

21. Gerasimov, A.C.; Esipovich, A.K.; Koshcheev, L.A.; Sulginov, N.G. Operating conditions study of Moscow power system during emergency development at May 2005. Elektrichestvo 2008, 1, 2-12. (In Russian)

22. Paris, L.; Valtorta, M.; Manzoni, E.A. Rapport de la mission d'enquete sur la panne d'electricite du 19 decembre 1978. Electr. France 1979, 1, 31-49.

23. Paris, L.; Zini, G.; Valtorta, M.; Manzoni, G.; Invernizzi, A.; De Franco, N.; Vian, A. Present limits of very long distance transmission systems. In Proceedings of the CIGRE 1984 Session, Paris, France, 29 August-6 September 1984; pp. 37-112.

24. Mueller, H.-C.; Haubrich, H.-J.; Schwarz, J. Technical limits of interconnected systems. In Proceedings of the CIGRE 1992 Session, Paris, France, 30 August-5 September 1992; pp. 37-301.

25. Amin, M. Challenges in reliability, security, efficiency, and resilience of energy infrastructure: Toward smart self-healing electric power grid. In Proceedings of the 2008 IEEE Power and Energy Society General Meeting-Conversion and Delivery of Electrical Energy in the 21st Century, Pittsburgh, PA, USA, 20-24 July 2008.

26. Voropai, N.I.; Bat-Undraal, B.; Enkhsaikhan, E. Ways and problems of micro-systems of power supply of isolated consumers in Mongolia. Izv. RAN Energ. 2019, 6, 43-50. (In Russian)

27. Vassiliev, S. Green roofs of Russia or micro-generation in Russia. Energy Econ. Tech. Ecol. 2018, 5, 69-72. (In Russian)

28. Voropai, N.; Rehtanz, C. Flexibility and Resiliency of Electric Power Systems: Analysis of Definitions and Content. In Proceedings of the EPJ Web of Conferences, International Workshop on Flexibility and Resiliency of Electric Power Systems, Irkutsk, Russia, 26-30 August 2019.

29. Marceau, R.J.; Endrenyi, J.; Allan, R.; Alvarado, F.L. Power system security assessment: A position paper. Electra 1997, 175, 49-77.

30. Zhang, X.-P.; Rehtanz, C.; Pal, B.C. Flexible AC Transmission Systems: Modelling and Control; Springer: Berlin, Germany, 2012.

31. Sun, H.; Wang, Y.; Nikovski, D.; Zhang, J. Flex-Grid: A dynamic and adaptive configurable power distribution system. In Proceedings of the 2015 IEEE Eindhoven PowerTech, Eindhoven, The Netherlands, 29 June-2 July 2015.

32. Chulyukova, M.; Voropai, N. Flexibility Enhancement in an Islanded Distribution Power System by Online Demand-Side Management. In Proceedings of the EPJ Web of Conferences, International Workshop on Flexibility and Resiliency of Electric Power Systems, Irkutsk, Russia, 26-30 August 2019.

33. Chen, X.; Kang, C.; O'Malley, M.; Xia, Q.; Bai, J.; Liu, C.; Sun, R.; Wang, W.; Li, H. Increasing the Flexibility of Combined Heat and Power for Wind Power Integration in China: Modeling and Implications. IEEE Trans. Power Syst. 2015, 30, 1848-1857.

34. Styczynski, Z.; Adamek, F.; Irovani, F.; Voropai, N. Electric Energy Storage System. CIGRE Brochure, WG C6.15; CIGRE Brochure: Paris, France, 2011.

35. Koeppel, G.; Andersson, G. The influence of combined power, gas, and thermal networks on the reliability of supply. In Proceedings of the 6th World Energy System Conference, Torino, Italy, 10-12 July 2006.

36. Shulginov, N.G.; Pavlushko, S.A.; Dyachkov, V.A. Effective control of electric power operating modes of UES of Russia in current conditions. Energetik 2013, 6, 20-24. (In Russian)

37. Lund, P.D.; Lindgren, J.; Mikkola, J.; Salpakari, J. Review of energy system flexibility measures to enable high levels of variable renewable electricity. Renew. Sustain. Energy Rev. 2015, 45, 785-807. [CrossRef]

38. Bistline, J. Turn Down for What? The Economic Value of Operational Flexibility in Electricity Markets. IEEE Trans. Power Syst. 2018, 34, 527-534. [CrossRef] 
39. Nan, C.; Sansavini, G.; Kröger, W.; Sansavini, G. Building an Integrated Metric for Quantifying the Resilience of Interdependent Infrastructure Systems. In Proceedings of the 9th International Conference on Critical Information Infrastructure Security, Limassol, Cyprus, 13-15 October 2011.

40. Wang, Y.; Chen, C.; Wang, J.; Baldick, R. Research on resilience of power systems under natural disasters-A review. IEEE Trans. Power Syst. 2016, 31, 1604-1612. [CrossRef]

41. Panteli, M.; Mancarella, P.; Trakas, D.N.; Kyriakides, E.; Hatziargyriou, N.D. Metrics and Quantification of Operational and Infrastructure Resilience in Power Systems. IEEE Trans. Power Syst. 2017, 32, 4732-4742. [CrossRef]

42. Kezunovic, M.; Overbye, T.J. Off the Beaten Path: Resiliency and Associated Risk. IEEE Power Energy Mag. 2018, 16, 26-35. [CrossRef]

43. Voropai, N.I. The problem of large electric power system survivability. In Proceedings of the IEEE Power Tech, Stockholm, Sweden, 18-22 July 1995.

44. Besanger, Y.; Eremia, M.; Voropai, N. Major grid blackouts: Analysis, classification, and prevention. Handbook of Electrical Power System Dynamics: Modeling, Stability, and Control; IEEE Press-Wiley: Hoboken, NJ, USA, 2013; pp. 789-863.

45. Sovalov, S.A.; Semenov, V.A. Emergency Control in Power Systems; Energoatomizdat: Moscow, Russia, 1988.

46. Bialek, J.W. Blackouts in the US / Canada and continental Europe in 2003: Is liberalisation to blame? In Proceedings of the 2005 IEEE St. Petersburg Power Tech, St. Petersburg, Russia, 27-30 June 2005.

47. Hines, P.; Apt, J.; Talukdar, S. Large blackouts in North America: Historical trends and policy implications. Energy Policy 2009, 37, 5249-5259. [CrossRef]

48. Pourbeik, P.; Kundur, P.; Taylor, C. The anatomy of a power grid blackout-Root causes and dynamics of recent major blackouts. IEEE Power Energy Mag. 2006, 4, 22-29. [CrossRef]

49. Martins, A.C.B.; Gomes, P.; Alves, F. Lessons learned in restoration from recent blackout incidents in Brazilian power system. In Proceedings of the CIGRE 2012 Session, Paris, France, 25-30 August 2011.

50. Li, B.; Gomes, P.; Baumann, R. Lessons learnt from recent emergencies and blackout incidents. Electra 2015, $279,66-73$.

51. Feltes, J.; Grande-Moran, C. Down, but Not Out: A Brief Overview of Restoration Issues. IEEE Power Energy Mag. 2014, 12, 34-43. [CrossRef]

52. Che, L.; Khodayar, M.; Shahidehpour, M. Only Connect: Microgrids for Distribution System Restoration. IEEE Power Energy Mag. 2014, 12, 70-81.

53. Voropai, N.I.; Kolosok, I.N.; Korkina, E.S.; Osak, A.B. Cyber-physical electric power systems: Transformation of properties and new problems. Avtom. I IT Energetike 2018, 110, 31-35. (In Russian)

54. Voropai, N.I.; Gubko, M.V.; Kovalev, S.P.; Massel, L.V. Development problems of digital energetics in Russia. Probl. Upr. 2019, 1, 2-14. (In Russian)

55. Mehrdad, S.; Mousavian, S.; Madraki, G.; Dvorkin, Y. Cyber-Physical Resilience of Electrical Power Systems Against Malicious Attacks: A Review. Curr. Sustain. Energy Rep. 2018, 5, 14-22. [CrossRef]

56. Hull, J.; Khurana, H.; Markham, T.; Staggs, K. Staying in control: Cybersecurity and the modern electric grid. IEEE Power Energy Mag. 2011, 10, 41-48. [CrossRef]

57. Khaitan, S.K.; McCalley, J.D. Cyber physical system approach for design of power grids: A survey. In Proceedings of the 2013 IEEE Power \& Energy Society General Meeting, Vancouver, Canada, 21-25 July 2013.

58. Cai, Y.; Cao, Y.; Li, Y.; Huang, T.; Zhou, B. Cascading Failure Analysis Considering Interaction Between Power Grids and Communication Networks. IEEE Trans. Smart Grid 2016, 7, 530-538. [CrossRef]

59. Ashby, W.R. An Introduction to Cybernetics; Chapman and Hall: London, UK, 1957.

60. Fardanesh, B. Future trends in power system control. IEEE Comput. Appl. Power 2002, 15, 24-31. [CrossRef]

61. Ilic, M.; Allen, H.; Chapman, W.; King, C.; Lang, J.; Litvinov, E. Preventing Future Blackouts by Means of Enhanced Electric Power Systems Control: From Complexity to Order. Proc. IEEE 2005, 93, 1920-1941. [CrossRef]

62. Ruano, A.; Ge, S.S.; Guerra, T.M.; Lewis, F.L.; Principe, J.; Colnaric, M. Computational intelligence in control. In Proceedings of the 19th IFAC World Congress, Cape Town, South Africa, 24-29 August 2014.

63. Voropai, N.I.; Kurbatsky, V.G.; Tomin, N.V.; Panasetsky, D.A. Intelligent Software for Preventing Large Emergencies in Power Systems; Nauka: Novosibirsk, Russia, 2016. (In Russian)

64. Gerasimov, A.S.; Koshcheev, L.A.; Kritskiy, V.A.; Lisitsyn, A.A. Automatic emergency control in power systems. Elektr. Stantsyji 2020, 1, 41-49. (In Russian) 
65. Olfati-Saber, R.; Fax, J.A.; Murray, R.M. Consensus and Cooperation in Networked Multi-Agent Systems. Proc. IEEE 2007, 95, 215-233. [CrossRef]

66. Qin, J.; Wan, Y.; Yu, X.; Li, F.; Li, C. Consensus-Based Distributed Coordination Between Economic Dispatch and Demand Response. IEEE Trans. Smart Grid 2018, 10, 3709-3719. [CrossRef]

Publisher's Note: MDPI stays neutral with regard to jurisdictional claims in published maps and institutional affiliations.

(C) 2020 by the author. Licensee MDPI, Basel, Switzerland. This article is an open access article distributed under the terms and conditions of the Creative Commons Attribution (CC BY) license (http://creativecommons.org/licenses/by/4.0/). 